Cell Research (2001); 11(1): 17--27

\title{
Differential screening and characterization analysis of the egg envelope glycoprotein ZP3 cDNAs between gynogenetic and gonochoristic crucian carp
}

\author{
FAN Lian Chun, Shu Ting YANG, JiAn FANG GUI*
}

State Key laboratory of Freshwater Ecology and Biotechnology, Institute of Hydrobiology, Chinese Academy of Sciences, Wuhan 430072, China

\begin{abstract}
Gynogenetic silver crucian carp, Carassius auratus gibelio, is an intriguing model system. In the present work, a systemic study has been initiated by introducing suppression subtractive hybridization technique into this model system to identify the differentially expressed genes in oocytes between gynogenetic silver crucian carp and its closely related gonochoristic color crucian carp. Five differential cDNA fragments were identified from the preliminary screening, and two of them are ZP3 homologues. Moreover, the full length ZP3 cDNAs were cloned from their oocyte cDNA libraries. The length of ZP3 cDNAs were 1378 bp for gyno-carp and 1367 bp for gono-carp, and they can be translated into proteins with 435 amino acids. Obvious differences are not only in the composition of amino acids, but also in the number of potential Olinked oligosaccharide sites. In addition, gyno-carp ZP3 amino acid sequence has an unexpected higher identity value with common carp (83.5\%) than that with the closely related gono-carp (74.7\%). The unique homology may be originated from the ancient hybridization. Northern blot analysis confirmed that expression of the ZP3 gene occurred exclusively in the oocytes. Because O-linked oligosaccharides on ZP3 have been demonstrated to play very important roles in fertilization, it is suggested that the extra O-linked glycosylation sites may be related to the unique sperm-egg recognition mechanism in gynogenesis.
\end{abstract}

Key words: Gynogenesis, suppression subtractive hybridization, glycoprotein, ZP3, oocyte maturation.

\section{INTRODUCTION}

Fertilization in animals is the trigger that initiates development, and results in a series of well-choreographed interactions between molecules located on the surfaces of egg and sperm[1, $2]$. Some cell surface proteins, such as zona pellucida glycoprotein ZP1, ZP2 and ZP3, acrosomal protein bindin, acrosin and lysin, and sperm plasma membrane protein $\alpha$ - and $\beta$-fertilin, have been identified to mediate the interaction process[2-8]. Although studies on the regulative factors have been carried out for more than a century, and important progress has been made in recent years, it remains one of the least un-

*Corresponding author: Jian Fang QUI

Fax: 0086-027-87875132; E-mail: jfgui@ihb.ac.cn

Revised July-17-2000 Revised Dec-10-2000 Accepted Jan-18- derstood fundamental biological processes. As suggested by Vacquier recently, novel methods and special model organisms will be still required for furthering the knowledge of fertilization mechanism[7].

Gynogenetic silver crucian carp (gono-carp), Carassius auratus gibelio, is a unique natural species that can reproduce by gynogenesis [9], [10]. Some special cytological phenomena have been revealed by a series of experiments. In artificial propagation, insemination by sperm of other species activates and initiates egg development, but the incorporated sperm nucleus remains condensed and does not transform into a male pronucleus[11]. When the naked eggs after removal of chorion envelope were inseminated with sperm of other fish, for example common carp, or when 
the treated heterologous sperm without plasma membranes and nuclear membranes were microinjected into mature eggs, sperm nuclei underwent decondensation, and transformed into male pronuclei[11-13]. These phenomena were also observed in Japanese gynogenetic crucian carp Carassius auratus langsdorfii[14]. The above findings suggested that sperm-egg interactions during the passage of sperm through egg envelope might play important regulative roles, and some protein factors on their surfaces should be involved. Therefore, the gynogenetic fish provides a unique model system for identifying sperm-egg recognition proteins and genes and for understanding the interaction mechanism between egg and sperm[10], [15], [16].

Recently, several PCR-based techniques for differential gene screening have been established [17-19]. One suppression subtractive hybridization (SSH) technique[19], owing to its high efficiency and rapidity, has been widely applied to many molecular cloning studies for the identification of disease, development, and tissuespecific, or other differentially expressed genes [20-24]. Because gyno-carp and gonochoristic color crucian carp (gono-carp), Carassius auratus, are closely related subspecies with different reproductive modes, we have, therefore, initiated a systemic study to use suppression subtractive hybridization technique to identify differential genes in oocytes between them. We herein report the differential screening and characterization analysis of an egg envelope glycoprotein cDNAs between the gyno-carp and gono-carp. The glycoprotein has been identified as homologues of ZP3 in mammals, bird, frog and fish.

\section{MATERIALS AND METHODS}

\section{Brood fishes and matured oocytes}

The brood fishes of gyno-carp, Carassius auratus gibeli, and gono-carp, Carassius auratus, were selected from Guanqiao Experimental Station, Institute of Hydrobiology, Chinese Academy of Sciences. During reproduction season, the selected brood fishes were artificially induced into maturation by two intraperitoneal injections with a mixture of acetone-dried carp pituitary, HCG and LRH-A as described previously[25]. Acetone-dried carp pituitary was self-made. HCG and LRH-A were purchased from Shanghai Lizhu Dong Feng Biotechnology Co. LTD. The first injection was $0.6 \mathrm{mg}$ carp pituitary, $600 \mathrm{IU}$ HCG and $6 \mu \mathrm{g} \mathrm{LRH}-$ $\mathrm{A} / \mathrm{kg}$ fish weight. The second injection was $0.4 \mathrm{mg}$ carp pituitary,
$200 \mathrm{IU}$ HCG and $2 \mu \mathrm{g}$ LRH-A/kg fish weight. The interval between two injections was $8 \mathrm{~h}$. Injected fishes were kept under natural water temperature of $16-18^{\circ} \mathrm{C}$. The matured eggs were obtained at $14 \mathrm{~h}$ post-injection.

\section{Total RNA and mRNA isolation}

Total RNAs were extracted from maturated oocytes, liver, heart, spleen and brain of the gyno-carp and gono-carp with QuickPrep total RNA extraction kit (Pharmacia, Cat. 27-927001), and the total RNA of oocytes were fractionated by oligo (dT)-cellulose chromatography with mRNA purification kit (Pharmacia, Cat. 27-9258-01) as described previously[16]. After detection by UV spectrophotometer and agarose gel electrophoresis, the purified mRNAs were used to synthesize cDNAs for cDNA library construction and subtraction hybridization.

\section{cDNA library construction}

About $5 \mathrm{mg}$ oocyte poly $(\mathrm{A})^{+}$mRNAs were used to synthesize directional double strand cDNAs using Timesaver cDNA synthesis kit (Pharmacia, Cat. 27-9262-01) along with directional cloning toolbox (Pharmacia, Cat. 27-9274-01). After EcoR I adaptor ligation and Not I digestion, the resulted directional cDNAs were inserted into lg t11 Sfi-Not cloning vector (Promega, Cat. T3230). Through in vitro packaging with packaging extracts (Promega, Cat K3152), we constructed the expressive cDNA libraries of gyno-carp and gono-carp. The titration were $3.1 \times 10^{6}$ pfu for gyno-carp and $1.6 \times 10^{6}$ pfu for gono-carp respectively[26].

\section{Driver and tester cDNA preparation}

Driver and tester cDNAs were prepared as described by Diatchenko et al.[19]. Briefly, ds cDNAs were respectively synthesized from $2 \mu \mathrm{g}$ each of gyno- and gono-carp oocyte poly(A) ${ }^{+}$mRNA using the PCR-selectTM cDNA subtraction kit (Clontech, Cat. K1804-1) and $1 \mu \mathrm{l}$ of CDS primer (5' TTTTGTACAAGCTT $\left.{ }_{30} \mathrm{~N} 1 \mathrm{~N}-3{ }^{\prime}\right)(10 \mu \mathrm{M})$. First- and secondstrand cDNA synthesis and blunt-ending of DNA ends by T4 DNA polymerase were carried out according to the manufacturer' s protocol. The resulting cDNAs were digested by Rsa I in a $50 \mu$ 1 reaction mixture containing 15 units of Rsa I enzyme for $3 \mathrm{~h}$. The cDNAs were then phenol-extracted, ethanol-precipitated, and resuspended in deionized water at a final concentration about $300 \mathrm{ng} / \mu \mathrm{l}$. The majority was used for driver cDNAs and stored at $-20^{\circ} \mathrm{C}$ for further use.

To prepare tester cDNA, gyno- and gono- carp cDNA $(1 \mu \mathrm{l})$ was respectively diluted in $5 \mu \mathrm{l}$ of deionized $\mathrm{H} 2 \mathrm{O}$. The diluted cDNA $(2 \mu \mathrm{l})$ was then ligated to $2 \mathrm{ml}$ of adapter 1

5'-CTAATACGACTCACTATAGGGCTCGAGCGGCCGCCCGGGCAGGT-3' 3' -GGCCCGTCCA-5'

and adapter $2 \mathrm{R}$

5'-CTAATACGACTCACTATAGGGCAGCGTGGTCGCGGCCGAGGT-3'

3' -GCCGGCTCCA-5'

$(10 \mu \mathrm{M})$ in separate ligation reactions in a total volume of $10 \mu$ l at $16^{\circ} \mathrm{C}$ overnight, using 0.5 units of T4 DNA ligase (Promega) in the buffer supplied from the manufacturer. After ligation, $1 \mu \mathrm{l}$ 
of $0.2 \mathrm{M} \mathrm{EDTA}$ ( $\mathrm{pH} 8.0$ ) was added and the samples were heated at $70^{\circ} \mathrm{C}$ for $5 \mathrm{~min}$ to inactivate the ligase. The prepared ds tester cDNAs were stored at $-20^{\circ} \mathrm{C}$ for further use.

\section{Subtractive hybridization}

For the subtracted cDNA of gyno-carp, 1.5 microliters of gono-carp driver ds cDNA (450 ng) was added to each of two tubes containing $1.5 \mu \mathrm{l}$ of adaptor1-ligated and adaptor $2 \mathrm{R}$ ligated gyno-carp tester cDNA ( $15 \mathrm{ng}$ ). The samples were mixed with $2 \mu \mathrm{l}$ of $4 \times$ hybridization buffer $(200 \mathrm{mM}$ Hepes, $\mathrm{pH} 8.3,2$ $\mathrm{M} \mathrm{NaCl}, 0.08 \mathrm{~m}$ M EDTA, pH 8.0, 40\% PEG8000). The solution was overlaid with mineral oil, the DNAs were denatured (1.5 $\min , 98^{\circ} \mathrm{C}$ ), and then allow to anneal for $10 \mathrm{~h}$ at $68^{\circ} \mathrm{C}$. After this first hybridization, the two samples were combined and a fresh portion of heat-denatured gono-carp driver cDNA (150 ng) in 1 . $5 \mu \mathrm{l}$ of hybridization buffer was added. The sample was allowed to hybridize for an additional $10 \mathrm{~h}$ at $68^{\circ} \mathrm{C}$. The final hybridization was then diluted in $200 \mu \mathrm{l}$ of dilution buffer ( $20 \mathrm{~m}$ M Hepes, $\mathrm{pH}$ $8.3 ; 50 \mathrm{~m} \mathrm{M} \mathrm{NaCl} ; 0.2 \mathrm{mM}$ EDTA), heated at $68^{\circ} \mathrm{C}$ for $7 \mathrm{~min}$ and stored at $-20^{\circ} \mathrm{C}$ For the subtracted cDNA of gono-carp, all the steps were same to the above except the added driver cDNA and tester cDNA were reversed.

\section{PCR amplification}

For each subtraction, two PCR amplifications were performed. The primary PCR was conducted in $25 \mu \mathrm{l}$. It contained $1 \mu \mathrm{l}$ of diluted, subtracted cDNA, $1 \mu \mathrm{l}$ PCR primer 1 (5' $^{\prime}$ CTAATACGACTCACTATAGGGC-3' ) (10 $\mu \mathrm{M}), 0.5 \mathrm{ml}$ dNTP $(10 \mathrm{~m} \mathrm{M}), 0.5 \mu \mathrm{l} 50$ advantage cDNA polymerase mix (Clontech Cat. 8417-1). PCR was performed with the following parameters: $75^{\circ} \mathrm{C}$ for $5 \mathrm{~min}$, then $94^{\circ} \mathrm{C}$ for $25 \mathrm{sec} ; 27$ cycles at $\left(94^{\circ} \mathrm{C}\right.$ for $10 \mathrm{sec}$, $66^{\circ} \mathrm{C}$ for $30 \mathrm{sec}, 72^{\circ} \mathrm{C}$ for $1.5 \mathrm{~min}$ ). The amplified products were diluted 10 -fold in deionized water. Some of the product $(1 \mathrm{ml})$ was used as a template in secondary PCR for 10 cycles under the same conditions used for the primary PCR, except PCR primer 1 was replaced with nested PCR primer 1 (5' TCGAGCGGCCGCCCGGGCAGGT-3' ) and nested PCR primer 2R (5' -AGCGTGGTCGCGGCCGAGGT-3' ).

\section{Cloning and analysis of the subtracted cDNAs}

Both subtracted products of gyno- and gono-carp from the secondary PCR were respectively inserted into pGEM-T vector (Promega, Cat. A3600). The subtracted cDNA libraries were then constructed by transformation of the ligated plasmids into competent DH5 $\alpha \mathrm{E}$. Coli. The colonies from the gyno- or gonosubtracted cDNA library were randomly picked, and grown each colony in $0.5 \mathrm{ml}$ of tube with $100 \mu \mathrm{l}$ of LB-amp medium at $37^{\circ} \mathrm{C}$ for 2-3 $\mathrm{h}$ with shaking. The cloned inserts in pGEM were amplified for 25 cycles using $1 \mathrm{ml}$ of each bacterial culture as template under similar conditions as in the secondary PCR described above. Amplified inserts ( $5 \mu \mathrm{l})$ from each clone were then mixed with equal volume freshly prepared $\mathrm{NaOH}(0.6 \mathrm{~N})$ to denature the DNA. $1 \mu \mathrm{l}$ of each mixture was transferred to a nylon membrane, and two identical blots were made for hybridizing with gyno- and gono-carp subtracted cDNA probes. The blotted membranes were neutralized for 5 min in $0.5 \mathrm{M}$ Tris- $\mathrm{HCl}(\mathrm{pH} 7$. 5), washed in $\mathrm{H}_{2} \mathrm{O}$. The DNA was cross-linked to the membrane by baking the blots for $2 \mathrm{~h}$ at $80^{\circ} \mathrm{C}$ in an oven.

Total subtracted cDNA mixture of gyno- and gono-carp were respectively used as probes to screen differential cDNA fragments between the two fishes. $1 \mu \mathrm{g}$ of each subtracted cDNA mixture was labeled with DIG high prime labeling and detection starter kit I (Boehringer Mannheim, Cat. 1745832) by random priming according to the manufacturer's protocol. Hybridization was performed in $10 \mathrm{ml}$ standard hybridization buffer (Boehringer Mannheim) using $25 \mathrm{ng} / \mathrm{ml}$ DIG-labeled cDNA mixture probes for $8-16 \mathrm{~h}$ at $69^{\circ} \mathrm{C}$. Membranes were washed at room temperature with $2 \times \mathrm{SSC}$ and $0.1 \% \mathrm{SDS}$ two times for $5 \mathrm{~min}$ each, and a high stringency wash with $0.1 \times$ SSC and $0.1 \%$ SDS at $68^{\circ} \mathrm{C}$ for two times for $15 \mathrm{~min}$.

After hybridization and stringency washes, the membranes were color-detected according the protocol in DIG high prime labeling and detection starter kit I. Differential fragments were selected through comparing the two identical membranes that hybridized with gyno- and gono-carp subtracted cDNA probes respectively.

Plasmid DNAs of the differential clones were prepared using Wizard Plus DNA purification system (Cat. No. A7100) according to manufacturer protocol. DNA sequencing was performed by the chain termination reaction with dRhodamine terminator cycle sequencing Kit (PE, Cat. 403042) at ABI PRISMTM 310 Genetic Analyzer (Perkin Elmer). Nucleic acid homology searches were performed using the BLAST program through Web servers at USA National Center for Biotechnology Information (National Institute of Health, Bethesda).

\section{Full length cDNA cloning}

Based on the sequences obtained from subtracted fragments, the cloned primers were designed and synthesized in Sangon Co (Shanghai). The primers were then used to amplify the $\lambda$ gt11cDNA libraries constructed by us before[26]. Amplified fragments were cloned and sequenced, and the full-length cDNA were obtained through patching the 5' and 3' coexistent sequences between the two fragments.

\section{Computer-aided sequence analysis}

The deduced amino acids, the predicted potential O-linked glycosylation sites and the signal peptide sites were all performed by using software on the ExPASy Web site[27]. Homologous comparison was performed by ClustalW 1.7 program.

\section{Northern blot analysis of the tissue specific ex- pression of $Z P 3$}

The subtracted ZP3 cDNA inserts of gyno- and gono-carp were respectively recovered by electrophoresis of the digested recombinant plasmids on $1.5 \%$ agarose gel. The probes were prepared by DIG high prime labeling and detection starter kit I (Cat. 1745832). The procedures for Northern blot referred to the report by Kim et al[28]. $20 \mu \mathrm{g}$ total RNAs extracted from each tissue, including oocytes, liver, spleen, heart and brain, were electrophoresed on $1.0 \%$ agarose gel containing $6 \%$ formaldehyde, and transferred to Hybond $\mathrm{N}^{+}$nylon membrane. The membrane was pre-hybridized in a solution containing $50 \%$ formamide, $1 \% \mathrm{SDS}, 10 \%$ dextran sulfate, and $1 \mathrm{M} \mathrm{NaCl}$ at $42^{\circ} \mathrm{C}$ 
for more than $1 \mathrm{~h}$. Hybridization was continued to overnight at $42^{\circ} \mathrm{C}$ in the presence of denatured probes and denatured salmon testes DNA at the final concentration of $50 \mu \mathrm{g} / \mathrm{ml}$. The procedures of membrane washing and color detection were same with the procedure described above.

\section{RESULTS}

Construction of the subtracted cDNA libraries and screening of the differential fragments

Using suppression subtractive hybridization technique, we prepared driver cDNAs and tester cDNAs of mature oocytes from gyno-carp and gono-carp respectively. After subtractive hybridization was performed from both forward (gynocarp as tester, gono-carp as driver) and reverse (gono-carp as tester, gyno-carp as driver) (Fig 1A), two subtracted cDNA libraries specific for the gyno- or gono-carp were generated by cloning the subtracted PCR products into pGEM-T plasmid. Partial clones selected randomly from two subtracted libraries were then subjected to differential screening using both subtracted cDNAs of gyno- and gono-carp as probes respectively. Of

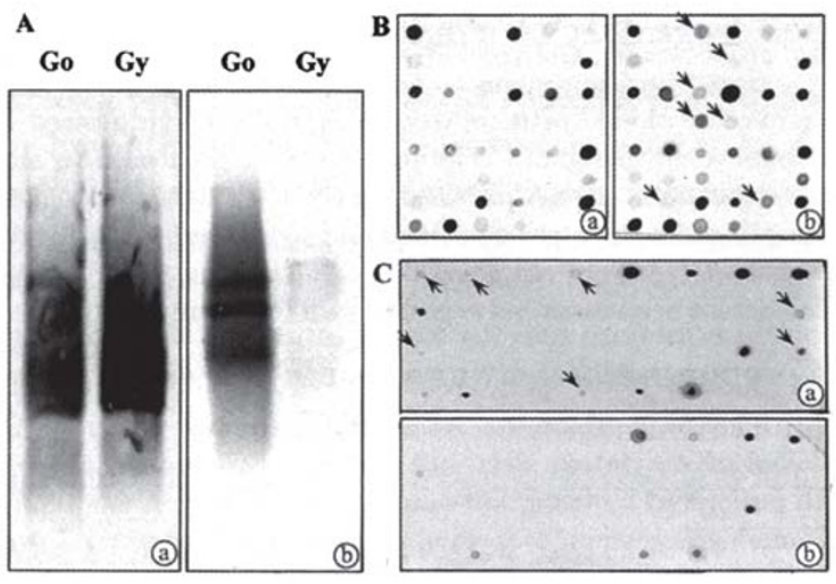

Fig 1. Construction of oocyte subtracted cDNA libraries from gyno-carp and gono-carp and screening of the differential cDNA fragments. (A) Northern blot analysis of subtracted efficiency. Unsubtracted (a) and subtracted (b) cDNAs of gono-carp (Go) and gyno-carp (Gy) driver cDNA were hybridized with the subtracted cDNA probes of gonocarp. (B) Cloned fragments from subtracted library of gonocarp were subjected to differential screening using subtracted cDNAs of gyno-carp (a) and gono-carp (b) as probes respectively. The arrows indicate differential clones specific for gono-carp. (C) Cloned fragments from subtracted library of gyno-carp were subjected to differential screening using subtracted cDNAs of gyno-carp (a) and gono-carp (b) as probes respectively. The arrows indicate differential clones specific for gyno-carp.
48 gono-carp clones screened, 7 differential clones pro- duced stronger hybridization signal with gono-carp cDNA probe than with gyno-carp cDNA probe (Fig 1B). Of 32 gyno-carp clones screened, 7 differential clones also produced stronger hybridization signal with gyno-carp cDNA probe than with gono-carp cDNA probe (Fig 1C). After eliminating 9 false positive clones, five positive clones were selected from the 14 differential clones through further screening by Northern blot analysis (data not shown).

Identification of differential ZP3 cDNA fragments specific for gyno-carp and gono-carp, and cloning of their full length $c D N A s$

Five cDNA insert fragments (termed as Gysub2, Gy-sub5, Go-sub32, Go-sub78 and Gosub107) were sequenced from the 5 positive clones. Sequencing results revealed that three of them (Gysub2, Go-sub32, Go-sub78) have no homologous sequences in the Genebank (being further studied in our laboratory), and other two (Gy-sub5 and Gosub107) have homology to that of primary sperm receptor ZP3 cDNA on egg envelope surfaces in mammals and Xenopus[29-31]. The cDNA fragment specific for gyno-carp locates at 5' terminal (as shown in Fig 2A), while the cDNA fragment specific for gono-carp locates at middle of the full length cDNA (as shown in Fig 2B).

In order to confirm the structural difference of ZP3 cDNAs between gyno-carp and gono-carp, we carried out Northern blot analysis for the gyno- and gono-carp poly $(\mathrm{A})(+)$-RNA using the identified specific cDNA fragments as probes. The specific gyno-carp probe identified differential messages that were much stronger in the gyno-carp than in the gono-carp (Fig 3A). The specific gono-carp probe also detected a stronger hybridization signal in the gono-carp than in the gyno-carp (Fig 3B). These data implicated that there do exist structural differences in the two ZP3 cDNAs.

Because ZP3 has been demonstrated to play important roles in fertilization and sperm-egg recognition interactions[3], [8], we first focused our research on cloning of the full-length cDNAs from the two different reproductive mode fishes. Based on nucleotide sequences of the ZP3 cDNA fragments, we designed and synthesized two con- 
servative primers (37584, 5' GCCACAGGGGTGTAGGTAAG-3' ; 37585, 5' AGCAATGGTCAGCTGATCCAG-3' ) for the two fishes. Combined with the forward and reverse sequencing primers located in the $\lambda$ gt11 Sfi-Not vector of the constructed libraries, we cloned the full-length cDNAs of the two fishes by PCR amplification of two cDNA libraries constructed from mature eggs of gyno-carp and gono-carp[26] (Fig 3C).

Nucleotide and deduced amino acid sequences of two ZP3 cDNAs from gyno-carp and gonocarp

The nucleic acid sequences and deduced amino acid sequences of two ZP3 cDNAs were shown in Fig 2. The full-length ZP3 cDNAs were 1378 bp and $1367 \mathrm{bp}$ long for gyno- and gono-carp respectively. In the two sequences, there was a

$\mathbf{A}$

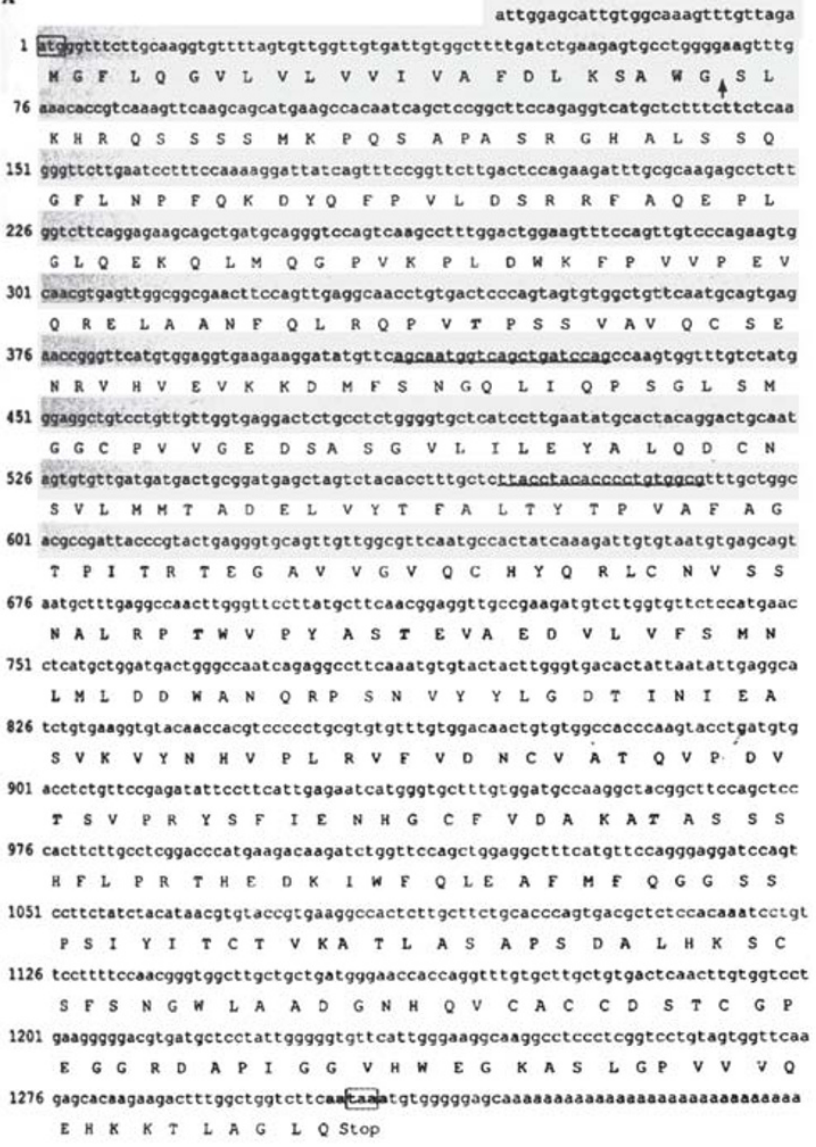

same length of $1308 \mathrm{bp}$ open reading frame encoding 435 amino acids. The transcripts both have a relatively short 5' untranslated region (29bp for gyno-carp and $21 \mathrm{bp}$ for gono-carp) followed by an open reading frame which commences with an ATG embedded in the ANNATG motif associated with vertebrate initiator codon[32]. The 3' untranslated regions were also very short, and the TAA termination codon is part of the canonical AATAAA polyadenylation signal which precedes the start of the poly(A) tail by 12nt (Fig 2).

Two subtracted cDNA fragments were found from the full-length sequences of the two ZP3 cDNAs. The 644-bp subtracted fragment specific for gyno-carp locates at 5' terminal from -29 to $615 \mathrm{bp}$ (Fig 2A). The 495-bp fragment specific for gono-carp locates at the middle from 393 to 887 bp. At digested ends of the subtracted fragments, the cut sites (GT/AC) of restriction enzyme Rsa I

B

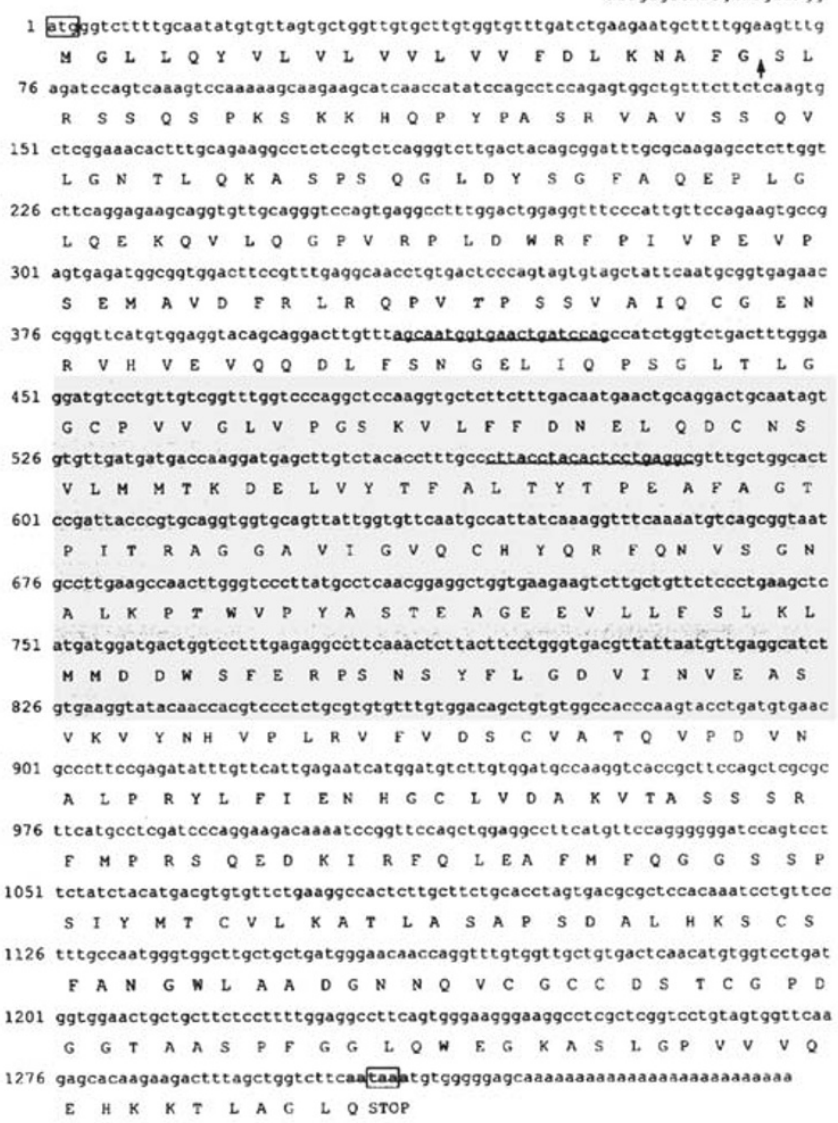

Fig 2. Nucleotide sequences and the predicted amino acid sequences of two ZP3 cDNAs from gyno- (A) and gono- (B) crucian carp. The shaded boxes show the subtracted fragments. The boxes show the initial codon and the terminal codon. The putative Nglycosylation site is underlined. The putative O-glycosylation threonine $(\mathrm{T})$ residues are in boldface. The polyadenylation signals (AATAAA) are also in boldface. The nucleotide sequences were deposited in GeneBank, accession No. AF180466 for the gyno-carp, and AF180465 for the gono-carp. 
were found, which results in different sizes of the subtracted fragments between two fishes. As indicated by homologous comparison between gyno- and gono-carp in Fig 4, 110 (25.3\%) amino acids are different among the total 435 amino acids between the two ZP3s. The homology values are $67.5 \%$ and $75.8 \%$ for the regions of gyno- (1-205) and gonocarp subtracted fragments (131-295). The values were not obviously higher than the average value, which means that the differences distribute randomly along the whole peptides, and cause the selection of two subtracted fragments of both ZP3 genes under the stringency hybridization parameters in this experiment.

\section{Comparison of structural characterization of two ZP3 proteins deduced from the $c D N A s$}

Both of the two ZP3 proteins deduced from the cloned cDNAs are composed of 435 amino acids,

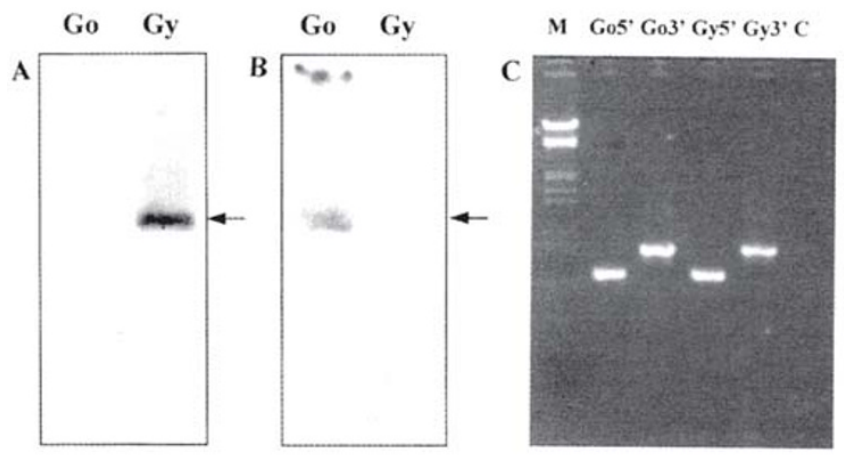

Fig 3. Identification and cloning of ZP3 cDNA differential fragments specific for gyno-carp and specific for gono-carp. (A) Northern blot screening of ZP3 mRNA (indicated by arrow) from the gyno-(Gy) and gono-(Go) crucian carp oocytes by the differential cDNA fragment specific for gynocarp as probe. (B) Northern blot screening of ZP3 mRNA (indicated by arrow) from the gyno- (Gy) and gono- (Go) crucian carp oocytes by the differential cDNA fragment specific for gono-carp as probe. (C) Cloning of full length of ZP3 cDNAs by PCR amplification from cDNA libraries constructed from mature eggs of gyno-carp and gono-carp. Lane $\mathrm{M}$ is standard molecular markers of $\lambda \mathrm{DNA} / \mathrm{HindIII}+\mathrm{EcoR}$ I; Gy5' and Go5' are amplified fragments by primer 37584 (5' -GCCACAGGGGTGTAGGTAAG-3' ) and forward sequencing primer on the $\lambda$ gt11 vector from the gyno- and gono-crucian carp libraries respectively; Gy3' and Go3' are amplified fragments by primer 37585 (5' AGCAATGGTCAGCTGATCCAG-3' ) and reverse sequencing primer on the $\lambda$ gt11 vector from the gyno- and gonocrucian carp libraries respectively; $\mathrm{C}$ is a negative control. with 15 amino acids more than common carp ( Cyprinus carpio) ZP3[33]. A cleavable signal-peptide sequence (data not shown) was predicted to be present at the $\mathrm{N}$ terminus (residues1-23) of both proteins by published method[34]. Hydropathy analysis[35] also identified an identical N-terminal signal sequence and similar hydropathy plots among gyno-carp, gono-carp and common carp

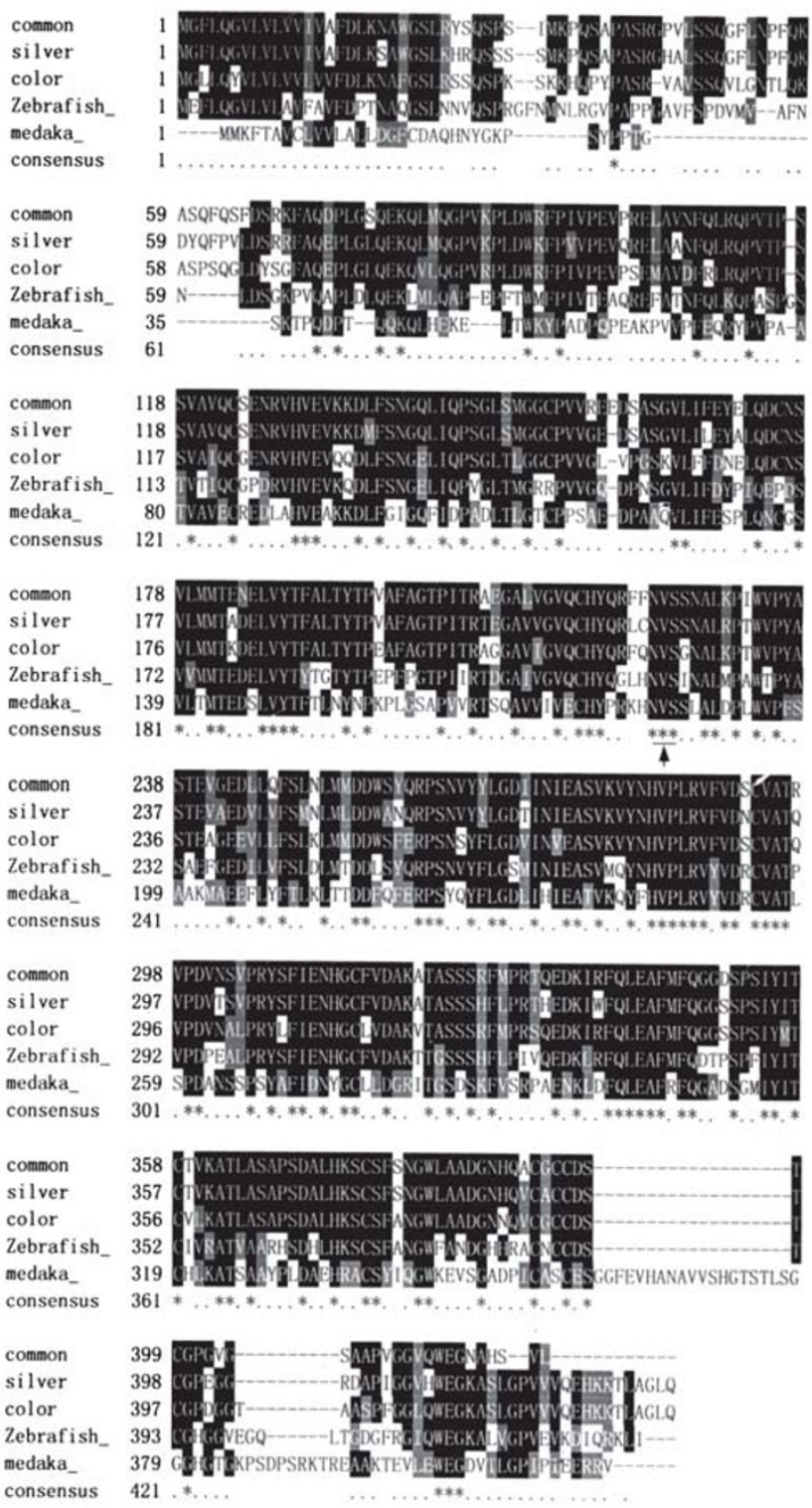

Fig 4. Multiple amino acid sequence comparison of ZP3 homologous from the gyno-carp (this paper), the gono-carp (this paper), the common carp[31], the zebrafish[40] and the medaka[30]. Homologous comparison and alignment were performed by ClustalW 1.7 program. Identical residues are black boxed. The conserved N-linked glycosation site (NVS) is indicated by arrow. 
(Fig 5A). Potential O-linked glycosylation sites (S or T) analyzed by NetOGlyc 2.0 program[36] revealed significant differences between the gynogenetic and gonochoristic fishes. In gono-carp and common carp, there are only two potential O-linked glycosylation sites (T114 and T230), whereas in gyno-carp, there are 5 potential O-linked glycosylation sites (T115, T231, T238, T301, and T321) (Fig 5B).

\section{Homology among fish ZP3 proteins and other} vertebrate $Z P$ proteins

A search of GeneBank database revealed that the ZP3 amino acid sequences of gyno- and gono- carp were homologous to that of the egg envelope glycoprotein ZP3 isolated from common carp[33], zebrafish[37], medake[38], Xenopus[31] and chicken[39], [40] and of mammalian zona pellucida ZP3 isolated from mouse[41] and human[42]. The level of sequence identity was found to be highly significant among a variety of fish species. Pairwise comparison of the amino acid sequences of gyno-carp ZP3 with homologues from common carp, zebrafish and medaka (Fig 4) revealed that identities over the entire length of the proteins range from $83.5 \%, 59.5 \%$ and $39.9 \%$ respectively. Similar comparison of the gono-carp ZP3 with the the above three fish species (Fig 4) indicated an

$\mathbf{A}$

Gy.

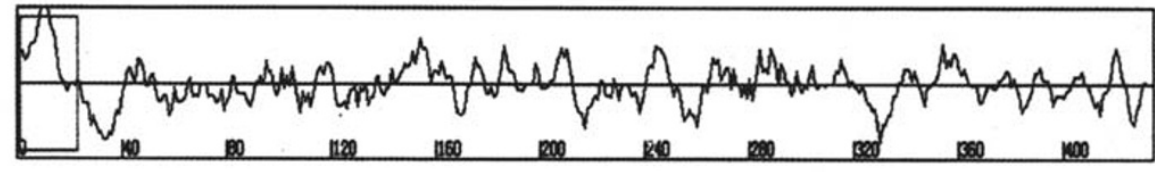

Go.

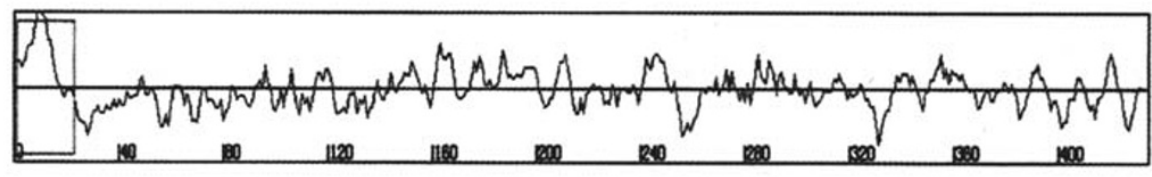

$\mathbf{B}$
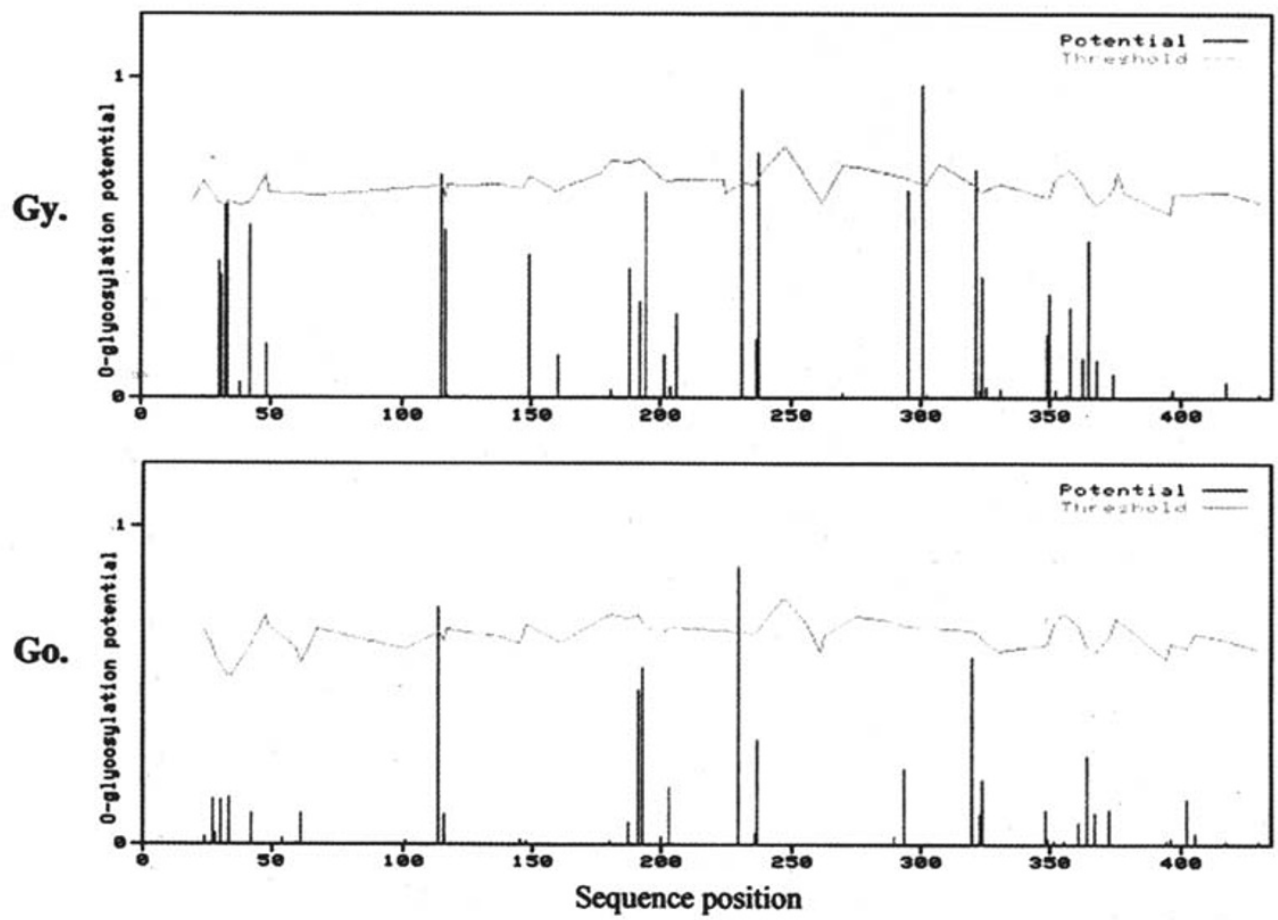

Fig 5. Comparison of hydropathy plots (A) and potential O-linked glycosylation sites (B) of gyno-carp (Gy) and gono-carp (Go) ZP3. Hydropathy plots were made by SOSUI system[38]. Hydrophobic domains are indicated by (+), hydrophilic domains by (-). A putative signal peptide (A, boxed) is present in the two sequences. Potential O-linked glycosylation sites were analyzed by NetOGlyc 2.0 program on the ExPASy Web site[39]. 
identity ranging from $74.0 \%, 55.9 \%$ and $43.6 \%$ respectively. Amino acid pairwise analysis further discovered an intriguing phenomenon. Among the total 435 amino acids, $325(74.7 \%)$ are identical between gyno-carp and gono-carp. The homology is $74.1 \%$ between gono-carp and common carp, but there is an unexpected higher identity (83.5\%) between the gyno-carp and common carp. These data may implicate that egg envelope ZP3 glycoprotein of gyno-carp is more closely related to the common carp than to gono-carp so far as ZP3 protein is concerned.

\section{Northern blot analysis of the two ZP3 mRNAs}

Northern blot analysis indicated that both gynocarp and gono-carp ZP3 mRNAs were expressed exclusively in their oocytes. No signals were detected from other tissues including liver, spleen, heart and brain (Fig 6).

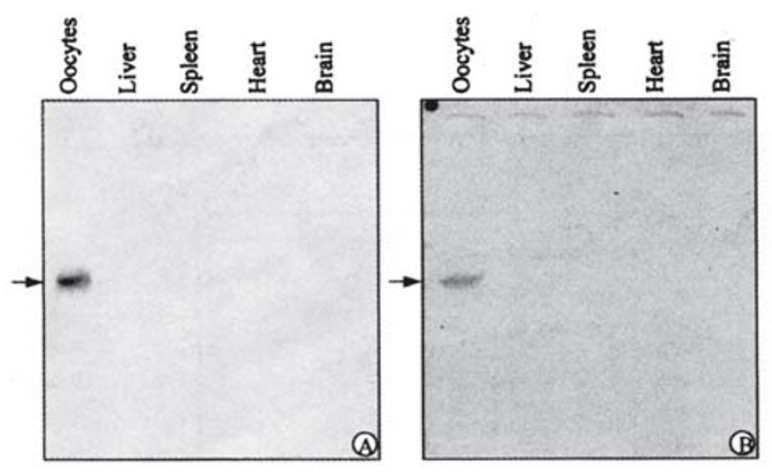

Fig 6. Northern blot analysis of the two ZP3 mRNAs. $20 \mathrm{mg}$ of total RNA isolated from each tissue, including matured oocytes, liver, spleen, heart and brain of female gyno-carp (A) and gono-carp (B), were electrophoresed, transferred onto a nitrocellular membrane, and hybridized with DIG-labelled partial fragments of the ZP3 cDNAs. Arrow indicates the hybridized signal.

\section{DISCUSSION}

Gynogenetic silver crucian carp had been classified as a subspecies of Carassius auratus. As similar to other gynogenetic fishes[43-45], the triploid gynoform was also demonstrated to be originated from an ancient hybridization event, and the maternal and paternal species might be Carassius auratus and Cyprinus carpio respectively[46]. In comparison with gonochoristic crucian carp, the major difference between them is the mode of reproduction. The substantial physiological difference must reflect the differential structure and expression of genes present in both oocytes. Using Suppression Subtractive Hybridization technique, we here constructed the subtracted cDNA libraries of two kinds of mature oocytes from gynogenetic and gonochoristic crucian carp. In 5 positively differential fragments screened from the subtracted libraries, two ZP3 cDNA fragments (one specific for gyno-carp, one specific for gono-carp) were first identified. Based on the sequences of two fragments, we cloned the full-length cDNAs from both gyno- and gono-carps by PCR amplification of the oocyte cDNA libraries constructed by us[26], and revealed the structure differences of ZP3 between them.

The most significant finding in the current studies is the realization that obvious differences exist not only in the sequences of ZP3 cDNAs and deduced amino acids, but also in the composition of amino acids and in the number of potential $\mathrm{O}$ linked oligosaccharides between gyno- and gonocarps. For example, in gyno-carp, there are 3 more potential O-linked glycosylation sites than in gonocarp located at 238th, 301st and 321st amino acid residues, besides two same potential O-linked glycosylation sites at 115 th and 231 st residues. In mouse, ZP3 has been demonstrated to serve as sperm receptor during binding of sperm to eggs[47]. And, the O-linked oligosaccharides play very important roles in the recognition and adhesion of sperm and eggs[48-51]. Additionally, we further analyzed the molecular characterization of goldfish ZP3 and common carp ZP3 published previously by others[33] (Genebank accession number Z48974 and Z48973), and only found one potential Olinked glycosylation site in these two species of gonochoristic fishes (data not shown). These data implicated that the extra O-linked glycosylation sites in the gyno- carp might be related to the unique sperm-egg recognition mechanism in gynogenesis. Fertilization is a complex process in which some cell surface proteins on the egg and sperm participate in a series of recognition and interaction procedures[8], [9]. Gynogenesis acts as an exceptional circumstance of fertilization, it should be regulated by a series of molecular interactions. The difference of ZP3 characterization revealed by this study 
has opened the door in which complicated mechanism has been locked for long time. A more interesting data on ZP2 difference between gyno- and gono-carp has been obtained recently by us (in preparation). Therefore, further biochemical and molecular studies on the egg envelope glycoproteins and their interaction with sperm surface proteins could be beneficial to explain the intriguing mechanism about both gynogenesis and fertilization.

Pairwise comparison of the deduced amino acid sequences of the gynogenetic and gonochoristic crucian carp ZP3 with homologues from other vertebrates suggested a common evolutionary origin for the glycoproteins. Several significantly conserved features, such as the NVS consensus site for Nlinked glycosylation, the numerous conserved cysteine residues, and the similar size of $\mathrm{N}$-terminal signal sequences, were revealed from all vertebrates including fish (Fig 4), amphibians, birds and mammals (data not shown). The hydropathy plots of these ZP3 are also similar. These conserved characteristics also imply their functional link and similar roles during fertilization among vertebrates, although there are obvious differences in the egg envelopes and fertilization processes among these various animals. Interestingly, the deduced amino acid sequence of gyno-carp ZP3 has an unexpected higher identity value with common carp (83.5\%) than that with gono-carp (74.7\%). This is obviously not in correspondence with the traditional classification system, in which gyno-carp and gono- carp belong to the same Carassius genus. Their evolutionary relationship should be more closely, and their homologous genes should have higher identity. In fact, some highly homologous genes, for example cell cycle regulator cyclin $\mathrm{A}$, have been recently confirmed by us between gyno- and gono-carps[26]. The unique homology of gyno-carp ZP3 with common carp may be explained by the ancient hybridization origin in which some paternal genetic information might be retained or recombined. Related evidence was also observed from gene expression of isozymes in the gynogenetic fish[46]. This current study has indicated that the mRNA of both crucian carp is synthesized in the oocytes, which is consistent with that in common carp[33]. In mammals, ZP3 is also synthesized in the growing oocytes and constitutes the egg envelope from the inside of the oocytes[4]. In contrast with crucian carp and mammals, however, ZP3 of another fish medaka ( Oryzias latipes) is synthesized only in liver but not in ovary of spawning female fish[38]. As shown by Waclawek et al., the chicken ZP3 is expressed exclusively in the granulosa cells surrounding oocytes[39]. Thereby, the idea that the difference in sites of synthesis of ZP proteins might be related to the differences in the biology of the reproductive efforts as suggested by Waclawek et al.[39] remains unsettled. Additionally, another intriguing feature of both crucian crap ZP3 cDNAs is that the 5' and 3' untranslated regions are unusually short, with a structure similar to that of mouse ZP3[41]. Generally, most 5' untranslated regions of eukaryotic genes range from 40 to $80 \mathrm{nt}$ and the 3 ' untranslated regions of most mRNAs are 50-150nt long[52]. Although the half-life of ZP3 RNA is not known, mouse ZP3 RNA does accumulate during oogenesis and represents $0.1-0.2 \%$ of the poly(A)+RNA in midsize oocytes. Furthermore, in the later stages of mouse oocyte growth and meiotic maturation the abundance of ZP3 mRNA falls off dramatically [53] and no zona protein synthesis is detectable in ovulated eggs[54], [55]. The expression of ZP3 in mouse is both tissue- specific and developmentally regulated[53]. Thus, the unusually short 5' and 3' untranslated regions might be important for the developmental regulation of ZP3, and our gynogenetic system may be a good model to examine the possible mechanisms controlling the expression of individual genes during vertebrate oogenesis and meiotic maturation.

\section{ACKNOWLEDGEMENTS}

These studies were supported by the National Natural Science Foundation of China (Grants No. 39700070 and 30070379), the Chinese Academy of Sciences (Grant No. KJ951-B1-607-03), and the Major State Basic Research Program (No. G1999053908) of China.

\section{REFERENCES}

[1] Wassarman PM. The biology and chemistry of fertilization. Science 1987; 235:553-560.

[2] Foltz KF, Lennarz WJ. The molecular basis of sea urchin gamete interactions at the egg plasma membrane. Dev Biol 1993; 158:46-61.

[3] Wassarman PM. Profile of a mammalian sperm receptor. 
Development 1990; 108:1-17.

[4] Whitaker M. Lighting the fuse at fertilization. Development 1993; 117:112.

[5] Barros C, Crosby JA, Moreno RD. Early steps of sperm-egg interactions during mammalian fertilization. Cell Biol Int Rev 1996; 20:33-9.

[6] Snell WJ, White JM. The molecules of mammalian fertilization. Cell 1996; 85:629-37.

[7] Vacquier VD. Evolution of gamete recognition proteins. Science 1998; 281:1995-8.

[8] Wassarman PM. Mammalian fertilization: molecular aspects of gamete adhesion, exocytosis, and fusion. Cell 1999; 96:175-83.

[9] Gui JF. A unique study system: gynogenetic fish Carassius auratus gibelio. Science Foundation in China 1996; 4: 44-6.

[10] Gui JF. Retrospect and prospects of studies on the mechanism of natural gynogenesis in silver crucian carp ( Carassius auratus gibelio). Bulletin of Natural National Science Foundation of China 1997; 11:11-6. (in Chinese)

[11] Ge W, Jiang YG. A preliminary study on the mode in the egg of the naturally gynogenetic crucian carp for inhibiting heterologous sperm from transforming into male pronucleus. Acta Hydrobiologica Sinica 1985; 9:203-8. (in Chinese)

[12] Ding J, Jiang YG, Shan SX, Wei LH. Roles of plasma membrane proteins of heterologous sperm in mediating primary control of gynogenetic silver crucian carp eggs. Chinese Science Bulletin 1993; 38:(in Chinese)

[13] Fan LC, Gui JF, Ding J, Zhu LF, Liang SC, Yang ZA. Cytological mechanism on the integration of heterologous genoe or chromosomes in the unique gynogenetic Carassius auratus gibelio. Dev Reprod Biol 1997; 6:3344.

[14] Yamashita M, Onozato H, Nakanishi T, Nagahama Y. Breakdown of the sperm nuclear envelop is a prerequisite for male pronucleus formation: Direct evidence from the gynogenetic crucian carp Carassius auratus langsdorfii. Dev Biol 1990; 137:155-60.

[15] Xie J, Zhu Y, Zhang F, Gui JF. Differential gene expression of protein kinases in oocytes between natural gynogenetic silver crucian carp and gonochoristic crucian carp. Chinese Science Bulletin 1999; 44: 1297-1301.

[16] Yang ZA, Li QH, Wang YF, Gui JF. Comparative investigation on spindle behavior and MPF activity changes during oocyte maturation between gynogenetic and amphimictic crucian carp. Cell research 1999; 9:145-54.

[17] Wang L, Brown DD. A gene expression screen. Proc Natl Acad Sci USA 1991; 88:11505-9.

[18] Liang P, Pardee AB. Differential display of eukaryotic messenger RNA by means of the polymerase chain reaction. Science 1992; 257:967-71.

[19] Diatchenko L, Lau YC, Campbell AP, Chenchik A, Mooadam F, Huang B, Lukyanov S, Lukyanov K, Gurskaya N, Sverdlov E, Siebert PD. Suppression subtractive hybridization: A method for generating differentially regulated or tissue- specific cDNA probes. Proc Natl Acad Sci USA 1996; 93:6025-30.

[20] Chu ZL, Mckinsey TA. Suppression of tumor necrosis factor-induced cell death by inhibitor of apoptosis c-
IAP2 is under NF-kB control. Proc Natl Acad Sci USA 1997; 94:10057-62.

[21] Davis CA, Benzer S. Generation of cDNA expression libraries enriched for in-frame sequences. Proc Natl Acad Sci USA 1997; 94:2128-32.

[22] Wong BR, Rho J, Arron J, Robinson E, Orlinick J, Chao M, Kalachikov S, Cayani E, Barlett III FS, Frankel WN, Lee SY, Choi Y. TRANCE is a novel ligand of the tumor necrosis factor receptor family that activates c-Jun Nterminal kinase in T cells. J Biol Chem 1997; 272:251904.

[23] Shimono A, Behringer RR. Isolation of novel cDNAs by subtractions between the anterior mesendoderm of single mouse gastrula atage embryos. Dev Biol 1999; 209:369-80.

[24] Evans JD, Wheeler DE. Differential gene expression between developing queens and workers in the honey bee, Apis mellifera. Proc Natl Acad Sci USA 1999; 96: 5575-80.

[25] Gui JF. Fish developmental genetics and Artificial propagation. In: Fish Genetics and Breeding Engineering (edited by Wu C and Gui JF), Shanghai Scientific and Technical Publishers, Shanghai, 1999; pp41-62. (in Chinese).

[26] Fan LC, Xie J, Wang Y, Gui JF. Construction of oocyte cDNA libraries of gynogenetic silver crucian carp and gonochoristic color crucian carp and cloning of their cyclin A1 cDNAs. Acta Hydrobiologica Sinica 2000; 24:573-81. (in Chinese).

[27] Nielsen H, Engelbrecht J, Brunak S, Heijne GV. Identifition of prokaryotic and eukaryotic signal peptides and prediction of their cleavage sites. Protein Engineering 1997; 10:1-6.

[28] Kim KS, Febbraio M, Han TH. Analysis of gene expression by blotting techniques. In Gene Probes 2: A Practical Approach (eds. Hames BD, Higgins SJ.), New York, Oxford University Press, 1995; pp156-165.

[29] Yurewicz E, Sacco A, Subramanian M. Structural characterization of the $\mathrm{Mr}=55,000$ antigen (ZP3) of porcine oocyte zona pellucida. J Biol Chem 1987; 262:564-71.

[30] Harris J, Hibler D, Fontenot G, Hsu K, Yurewicz E, Sacco A. Cloning and characterization of zona pellucida genes and cDNAs from a variety of mammalian species: the ZPA, ZPB and ZPC gene families. DNA Seq 1994; 4:36193.

[31] Yang J, Hedrick J. cDNA cloning and sequence analysis of the Xenopus laevis egg envelope glycoprotein gp43. Dev Growth Differ 1997; 39:457-67.

[32] Kozak M. Point mutations define a sequence flanking the AUG initiator codon that modulates translation by eukaryotic ribosomes. Cell 1986; 44:283-92.

[33] Chang YS, Wang SC, Tsao CC, Huang FL. Molecular cloning, structural analysis, and expression of carp ZP3 gene. Mol Reprod Dev 1996; 44:295-304.

[34] von Heijne G. A new method for predicting signal sequence cleavage site. Nucleic Acids Res 1986; 14: 4683-90.

[35] Hirokawa T, Boon-Chieng S, Mitaku S. SOSUI: Classification and Secondary Structure Prediction System for 
Membrane Proteins. Bioinformatics (formerly CABIOS) 1998; 14(4):378-9.

[36] Hansen JE, Lund O, Rapacki K, Brunak S. O-glycbase version 2.0 - A revised database of O-glycosylated proteins. Nucleic Acids Res 1997; 25: 278-282.

[37] Wang H, Gong Z. Characterization of two zebrafish cDNA clones encoding egg envelope proteins ZP2 and ZP3. Biochim Biophys Acta 1999; 1446:156-60.

[38] Murata K, Sasaki T, Yasumasu S, Iuchi I, Enami J, Yasumasu I, Yamagimi K. Cloning of cDNAs for the precursor protein of a low-molecular-weight subunit of the inner layer of the egg envelope (chorion) of the fish Oryzias latipes. Dev Biol 1995; 167:9-17.

[39] Waclawek M, Foisner R, Nimpf J, Schneider WJ. The chicken homologue of zona pellucida protein-3 is synthesized by granulosa cells. Biol Repro 1998; 59:12309.

[40] Takeuchi Y, Nishimura K, Aoki N, Adachi T, Sato C, Kitajima K, Matsuda T. A 42-kDa glycoprotein from chicken egg-envelope, an avian homolog of the ZPC family glycoproteins in mammalian Zona pellucida. Its first identification, cDNA cloning and granulosa cell-specific expression. Eur J Biochem 1999; 260:736-42.

[41] Ringuette MJ, Chamberlin ME, Baur AW, Sobieski DA, Dean J. Molecular analysis of cDNA coding for ZP3, a sperm binding protein of the mouse zona pellucida. Dev Biol 1988; 127:287-95.

[42] Van-Duin M, Polman J, Verkoelen C, Bunschoten H, Meyerink J, Olijve W, Aitken R. Cloning and characterization of the human sperm receptor ligand ZP3: evidence for a second polymorphic allele with a different frequency in the Caucasian and Japanese populations. Genomics 1992; 14:1064-70.

[43] Avise JC, Trexvis JC, Travis J, Nelson WS. Poecilia mexicana is the recent female parent of the unisexual fish Poecilia formosa. Evolution 1991; 45:1530-3.

[44] Schartl M, Nanda I, Schlupp I, Wilde B, Epplen JT, Schmid M, Parzefall J. Incorporation of subgenomic amounts of host species DNA in the gynogenetic Amazon Molly. Nature 1995; 373:68-71.

[45] Schlupp I, Nanda I, Dobler M, Lamatsch DK, Epplen JT, Parzefall J, Schmid M, Schartl M. Dispensable and indispensable genes in an ameiotic fish, the Amazon molly
Poecilia formosa. Cytogenet Cell Genet 1998; 80:193-8.

[46] Zhu L, Gui JF. Comparative studies on gene expression of isozymes in the 4 types of various ploidy crucian carp during embryogenesis. Acta Biologiae Experimentalis Sinica 1998; 31(4):369-76. (in Chinese)

[47] Wassarman PM, Litscher ES. Sperm-egg recognition mechanisms in mammals. Curr Top Dev Biol 1995; 30: 1-19.

[48] Bleil JD, Wassarman PM. Structure and function of the zona pellucida: identification and characterization of the proteins of the mouse oocyte's zona pellucida. Dev Biol 1980; 76:180-202.

[49] Kinloch RA, Sakai Y, Wassarman PM. Mapping the mouse ZP3 combing sites for sperm by exon swapping and site-directed mutagenesis. Proc Natl Acad Sci USA 1995; 92:263-7.

[50] Litscher ES, Wassarman PM. Characterization of a mouse ZP3-derived glycopeptides, gp55, that exhibits sperm receptor and acrosome reaction-inducing activity in vitro. Biochemistry 1996; 35:3980-5.

[51] Chen J, Litscher ES, Wassarman PM. Inactivation of the mouse sperm receptor, mZP3, by site-directed mutagenesis of individual serine residues located at the combining-site for sperm. Proc Natl Acad Sci USA 1998; 95: 6193-7.

[52] Kozak M. Comparation of initiation of protein synthesis in prokaryotes, eukaryotes, and organelles. Microbiol Res 1983; 47:1-45.

[53] Philpott CC, Ringuette MJ, Dean J. Oocyte-specific expression and developmental regulation of ZP3, the sperm receptor of the mouse zona pellucida. Dev Biol 1987; 121:568-75.

[54] Bleil JD, Wassarman PM. Galactose at the nonreducing terminus of O-linked oligosaccharides of mouse egg zona pellucida glycoprotein ZP3 is essential for the glycoprotein' s sperm receptor activity. Proc Natl Acad Sci USA 1988; 85:6778-82.

[55] Schmizu S, Tsuji M, Dean J. In vitro biosynthesis of three sulfated glycoproteins of murine zonae pellucidae by oocytes grown in follicle culture. J Biol Chem 1983; 258: 5858-63. 